\title{
Problems of Population Ageing in Large Cities
}

\author{
Elena Mirgorodskaya \\ Don State Technical University \\ IT and Economic Systems Faculty \\ Rostov-on-Don, Russia \\ emirgorod@mail.ru
}

\author{
Olesya Guzenko \\ Don State Technical University \\ IT and Economic Systems Faculty \\ Rostov-on-Don, Russia \\ guzenko_post@mail.ru
}

\begin{abstract}
This article is dedicated to population ageing which is one of the pressing global challenges of modern society development. It considers age structure changes in the largest Russian million-plus cities. Statistical data analysis not only made it possible to describe the ageing of the country's population but also revealed peculiarities of this phenomenon in large agglomerations. This allowed the authors to describe causes and tendencies of population ageing, assess its consequences and propose recommendations for reducing the impact of this phenomenon on the social and economic system of a large city.
\end{abstract}

Keywords - population ageing, birth rate, life expectancy, agglomeration, large city

\section{INTRODUCTION}

One of the global challenges for the modern economy is population ageing which has a number of serious consequences for the sustainable development of the social and economic system of cities and especially large agglomerations being "points of reference" for the development of the national economy. Population ageing is not only a demographic but also particular social and economic process which influences the urban development dynamics and urban governance model. As far as population ageing consequences are concerned, the following externalities of this process in the development of social and economic urban institutions shall be highlighted:

- Increase in the number of the unemployed population relative to the number of the employed population leads to a shortage of employees both at enterprises constituting the basis of integration processes in the agglomeration and in services for aged people.

- Increase in budget expenditures for retirement benefits, medical care and social services requires increasing the tax burden which, however, reduces living standards of the working population.

- Changes in the consumer demand structure lead to the need for structural changes in the regional economy.
- Many aged people living in cities are in need of the accessible environment, vehicles for passengers with reduced mobility etc. which requires increasing budget expenditures.

- Local authorities shall constantly analyse and consider the needs of aged people and include them in municipal program documents.

\section{MATERIALS AND METHODS (MODEL)}

The most common view of population ageing is that this phenomenon is considered in couple with the birth rate decline. It is believed that the combination of these factors leads to demographic and economic crises with the latter featured by the depletion of the pension fund resources and leading to the increase in the retirement age. This approach to population ageing is most relevant in Russia since, according to a number of such Russian authors as I.I. Abalgaziev, I.V. Ilyin, S. Vasin and E.N. Novoselova [1], [2], [3], it is the birth rate decline that is the main cause of a large gap between the number of young and aged people or the so-called ageing "from below" (Figure 1).

Despite the active demographic policy on the part of the government this problem remains and is forecast to get worse. In 2017, the birth rate in Russia decreased by $10.7 \%$ with about 1.69 million children born which is 203,000 children less year on year. At the same time, the cause of population ageing in developed countries is mostly the mortality rate decline.

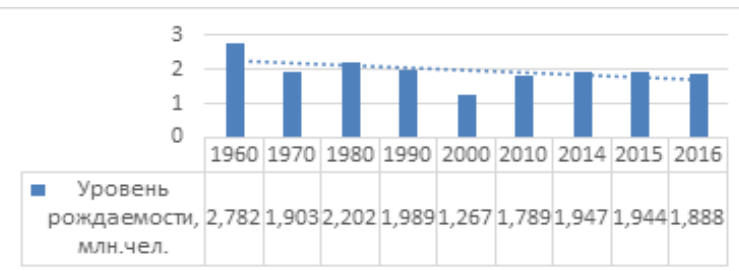
[5] 
Western European countries, the United States and Japan were first to face population ageing. Nowadays, the structure of the European population by age groups is changing rapidly. The tendency for life expectancy to grow, which is still steady in developed countries, sprang up in the United States and Japan at the beginning of the $20^{\text {th }}$ century and certainly is an achievement of mankind. Since the mid- $20^{\text {th }}$ century life expectancy of a European person has increased by eight years and is forecast to increase by another five years by 2050 .

Foreign social and economic works focus specially on population ageing in large cities considering not only the current expansion of this phenomenon but also the creation of tools for managing this process and special adaptive mechanisms of urban development. It is worth paying attention to the following works by Western economists, sociologists and demographers who consider the challenge from different points of view: [6], [7], [8], [9], [10], [11].

The purpose of this study is to identify the level of population ageing in the largest Russian cities and create a portfolio of adaptive institutional changes required to address this challenge. Official materials of the Federal State Statistics Service of the Russian Federation and analytical and consulting agencies were used to prepare and conduct this study. Statistics, comparison, description, generalization and data organisation methods of theoretical and empirical analysis were used during the study.

The following coefficient was used to evaluate population ageing in Russian agglomerations:

$$
\mathrm{W} 60=(\mathrm{S} 60+) / \mathrm{S} \times 100
$$

with $S 60+$ being the number of aged people of $60+$ years of age and $\mathrm{S}$ being the total population.

The Rosset-Boget-Garnier demographic ageing scale was used for interpreting population ageing (Table I).

TABLE I. Rosset-Boget-Garnier demographic ageing scale

\begin{tabular}{|l|l|}
\hline $\begin{array}{l}\text { Proportion of aged people } \\
(\mathbf{6 0}+\mathbf{)}\end{array}$ & Stages and levels of population ageing \\
\hline$<8$ & Demographic youth \\
\hline $8-10$ & Early stages of ageing \\
\hline $10-12$ & Proper ageing \\
\hline $12+$ & Demographic old age \\
\hline $12-14$ & Low level of demographic old age \\
\hline $14-16$ & Medium level of demographic old age \\
\hline $16-18$ & High level of demographic old age \\
\hline $18+$ & Very high level of demographic old age \\
\hline
\end{tabular}

\section{RESULTS AND DISCUSSION}

The development of medicine and the promotion of a healthy lifestyle result in life expectancy gradually increasing and the population ageing "from above" (Table II). This tendency is reflected in the study by V.K. Gostishchev and N.S. Glagolev [12].

TABLE II. List of countries by average life expectancy in 2017 [13]

\begin{tabular}{|l|l|l|}
\hline Rank & Country & Life expectancy \\
\hline 1 & Andorra & 82.75 \\
\hline 2 & Japan & 82.15 \\
\hline 3 & San Marino & 82 \\
\hline 4 & Singapore & 82 \\
\hline 5 & France & 81 \\
\hline 6 & Australia & 80.7 \\
\hline 7 & Switzerland & 80.7 \\
\hline 8 & Sweden & 80.7 \\
\hline 9 & Iceland & 80.45 \\
\hline 10 & Canada & 80.45 \\
\hline & $\ldots$ & \\
\hline $\mathbf{1 2 9}$ & Russia & $\mathbf{6 6 . 0 5}$ \\
\hline & $\ldots$ & \\
\hline 192 & Swaziland & 32.2 \\
\hline
\end{tabular}

Despite the fact that life expectancy in Russia is gradually increasing throughout its territory the table above shows that the country ranks $129^{\text {th }}$ out of 192 countries. According to a forecast until 2031 by the Federal State Statistics Service of the Russian Federation, the number of people of over working age will continue to grow in Russia (Table III).

TABLE III. Over working age population (at beginning of year) [5]

\begin{tabular}{|l|l|l|}
\hline Year & $\begin{array}{l}\text { Over working age } \\
\text { population }\end{array}$ & $\begin{array}{l}\text { Over working age } \\
\text { population per 1000 } \\
\text { working age people }\end{array}$ \\
\hline 2020 & $38,915,000.1$ & 480.5 \\
\hline 2023 & $40,311,000.7$ & 507.4 \\
\hline 2026 & $41,155,000.7$ & 520.9 \\
\hline 2031 & $42,324,000.2$ & 533.8 \\
\hline
\end{tabular}

Population reproduction in post-Soviet Russia is covered in works by A.I. Antonov, S.A. Sorokin and V.M. Medkov [14], [15], [16]. We can conclude on their basis that urban population ageing is exacerbated by a negative impact of social and economic and political upheavals of the $20^{\text {th }}$ century. Nowadays, the demographic situation is such that the population of 1960-1970 featured by the increase in the birth rate is approaching its retirement age while today's workforce is represented by the generation of the late 1980s and 1990s when a catastrophic decrease in the population birth rate occurred (Figure 2). 


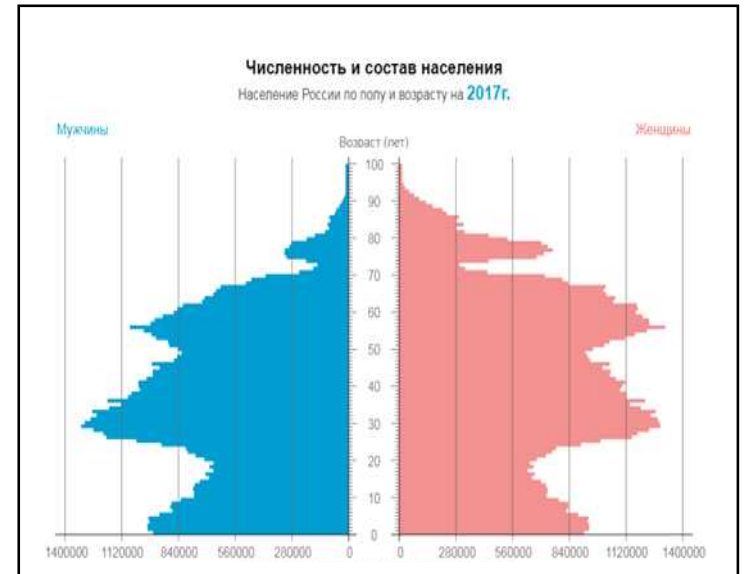
[5]

Fig.2. Russia's population pyramid of 2017 by sex and age

All this leads to the inevitable increase in the demographic burden as well as the increase in social expenditures for the support of the aged population.

If we consider population ageing in urban agglomerations, we will see that despite the vast territory which is largely distinguished by climate, infrastructure development, population income and social services quality, all this practically does not affect the intensity of population ageing.

By estimating population ageing in Russian agglomerations (the largest ones with the population of over 1 million people), on the basis of the Rosset-Boget-Garnier scale we came up with the following data (Table IV).

The population of 14 out of the 15 largest Russian agglomerations corresponds to various degrees of the demographic old age indicator. At the same time, a third of the agglomerations have a very high level of demographic old age and none is featured by demographic youth.

TABLE IV. Population ageing in largest Russian agglomerations.

\begin{tabular}{|l|l|l|}
\hline No. & Agglomeration & $\begin{array}{l}\text { Population } \\
\text { coefficient }\end{array}$ \\
\hline 1 & Moscow & 11.5 \\
\hline 2 & Saint-Petersburg & 15.3 \\
\hline 3 & Novosibirsk & 20 \\
\hline 4 & Nizhny Novgorod & 14.5 \\
\hline 5 & Samara-Tolyatti & 13 \\
\hline 6 & Rostov-on-Don & 17 \\
\hline 7 & Yekaterinburg & 19 \\
\hline 8 & Kazan & 13.3 \\
\hline 9 & Chelyabinsk & 17 \\
\hline 10 & Volgograd & 18 \\
\hline 11 & Ufa & 17 \\
\hline 12 & Voronezh & 15.2 \\
\hline 13 & Saratov & 19.8 \\
\hline 14 & Omsk & 21 \\
\hline 15 & Perm & 20 \\
\hline
\end{tabular}

In general, in terms of population ageing Russia's largest agglomerations may be divided into the following groups:
1. Agglomerations at early stages of ageing (Moscow agglomeration).

2. Agglomerations with a low level of demographic old age (Samara-Tolyatti and Kazan agglomerations).

3. Agglomerations with a medium level of demographic old age (Saint-Petersburg and Voronezh agglomerations).

4. Agglomerations with a high level of demographic old age (Rostov-on-Don, Chelyabinsk, Volgograd and Ufa agglomerations).

5. Agglomerations with a very high level of demographic old age (Yekaterinburg, Saratov, Omsk and Perm agglomerations).

Although the Moscow agglomeration is on the border of population ageing, it has unfavorable demographic conditions. For example, despite a slight increase in the birth rate in Moscow from 11.7 children per 1000 people in 2015 to 11.8 in 2016 it is still considered the lowest relative to national indicators. It is worth noting that in 2015-2016 the mortality rate did not change and the average life expectancy reached 77.7 years. Thus, population ageing in Moscow is due to the aforementioned factors. The birth rate is not enough to ensure stable simple reproduction of the population and the improvement of living standards and medical care leads to the increase in life expectancy.

It is important to note here that high living standards in the Moscow agglomeration and a number of job opportunities attract a large number of internal and external labor migrants not only to Moscow but also to such smaller cities included in the agglomeration as Balashikha, Khimki, Domodedovo, Shchyolkovo, Sergiyev Posad etc. These cities ensure the growth of the agglomeration's population. At the same time, incoming migrants are mostly of working and childbearing age, and $50 \%$ of them have not reached 30 years of age. For this reason, population ageing indicators in the Moscow agglomeration are relatively low but inaccurate as more than one-seventh of all Moscow children have migrant parents [3] not permanently residing in the city. Registry offices document their birth which results in the overestimation of the birth rate. Thus, the number of newborns increases but the population of the Moscow agglomeration does not.

As for the Samara-Tolyatti and Kazan agglomerations, these territorial entities are located in close proximity to each other and have many similar features. They are featured by common industrial, recreational and cultural relations and rich investment, human resources and cultural potential. Over the recent decades both the birth and mortality rates have been increasing in these regions. However, the total growth of these agglomerations' population is on the one hand largely due to migration inflows, and on the other hand due to the attachment of new settlements to cities (like Yudino and Derbyshki to Kazan). The proximity of Kazan to the northwestern border of the Tatarstan Republic influences the intensity of pendulous migration of the working population, a large flow of dacha owners and other agglomerative relations with neighboring regions, for example, with the Mari El Republic. 
The Samara-Tolyatti agglomeration is also featured by the positive migration increase which is due to the fact that the Samara region has an advantageous geographical location and is an investment-attractive region. All this increases the flow of migrants from neighboring countries and leads to the growth of the agglomerations' working though not permanent population.

The foregoing shows that the mechanical population growth exceeds the natural population growth in these agglomerations even with birth rates being higher than in other large cities and that such tendency requires careful consideration of the demographic situation.

Monocentricity is a distinctive feature of the St. Petersburg agglomeration. Accordingly, the density of the permanent population of the entire agglomeration is 9 times lower than that of the "central core," and therefore, as in the case of the Moscow agglomeration, it is very difficult to estimate its population. In 2017, the birth rate in the St. Petersburg agglomeration fell by $10 \%$, and the natural population growth decreased by $50 \%$ year on year. The mortality rate has practically not changed. However, the number of residents has increased by 63,000 people due to migration.

The mortality rate exceeded the birth rate in the Voronezh agglomeration in the first half of 2017, and the natural population decline amounted to 1,112 people with the Voronezh region ranking among the regions with the lowest birth rate in the country. At the same time, the average life expectancy increased to 72.8 years thus influencing population ageing. Migration is once again the only factor that keeps the demographic situation from being catastrophic. According to the Voronezhstat (the Voronezh Region Department of the Federal State Statistics Service of the Russian Federation), in 2017 , the number of migrants increased by 9,500 people. We should note that $100 \%$ of migrants came from other countries, mainly from the CIS states.

Thus, we can see that agglomerations with low and medium levels of demographic old age are united by the common migration tendency "rejuvenating" their population. However, migration is not a solution to urban population ageing and requires a municipal policy aimed at strengthening the family institution and increasing the birth rate among the native population.

Agglomerations with a high level of demographic old age are united by the decline in the birth rate, the mortality rate (or the fact that it remains the same) and migration which is no longer able to cover the natural population decline which leads to the reduction of the number of residents of large cities. For example, in 2017, the Chelyabinsk agglomeration saw a sharp demographic decline. 23,400 people were born and 27,300 people died in January-July 2017 which means that the natural population decline amounted to 3,900 people. External migration, however, failed to result in the positive population growth as during the same period 53,805 people left the agglomeration which is by 1454 people more than those 52,351 who arrived.

The birth rate is about 1.6 times lower than the one required to keep the current population in the Volgograd agglomeration. In the short term a few large adjacent localities will have to be attached to Volgograd to save its status of a million city.

Population ageing in the Ufa agglomeration is not only caused by the declining birth rate but also by the outflow of the native population. For example, in 2016, more than 46,000 people left for other regions. Most importantly, the majority of them are of working and childbearing age.

The Rostov-on-Don agglomeration does relatively well in this group with its core population steadily growing. However, the same cannot be said about cities in the agglomeration belts. And given the decline in the birth rate and migration in the Rostov region, this agglomeration also has a tendency for population ageing.

Agglomerations with a very high level of demographic old age are subject to the same birth rate decline tendency while migration is mainly featured by intra-agglomeration flows of the working population. In general, the population moves towards the center of the agglomeration (it is often pendulous migration).

As far as the outer area of agglomerations is concerned, we should note that, in general, the population moves closer to the center. Therefore, the largest migration increase is seen in the first agglomeration belt. Migration in the third belt is featured by the departure of the working population from small towns and villages closer to the center.

Thus, demographic processes occurring within the largest Russian agglomerations have both common tendencies related to the birth rate decline and population ageing and differences in migration flows which predetermine the need to establish regional and municipal policies based on the features of each agglomeration. At the same time, the issue of the quality of life of the ageing population with life expectancy steadily growing throughout the country is of great importance.

\section{CONCLUSION}

Ageing, as such, is considered a rather positive phenomenon as the increase in life expectancy means social progress. This was a major achievement of the last century for European societies. However, this improvement in the quality of a person's life brings additional financial and social externalities which should be undertaken by society. Politicians and regional leaders should acknowledge positive aspects of this process but it is necessary to establish a policy based on awareness of the problems it causes.

It should be noted that this challenge needs to be addressed at all levels of government. At the federal level, it is necessary to carry out a demographic policy aimed at increasing the birth rate and reform the pension and health care systems. City administrations in their turn also have the opportunity to take a whole range of measures to prevent difficulties caused by population ageing and address challenges in the following areas:

1. Supporting the economic activity of the aged population is an important condition for achieving its independence and long-term social activity. This, in turn, requires appropriate incomes for aged people to ensure the maximum satisfaction 
of their needs. At the municipal level, it is possible to create special jobs for pensioners which could provide them with additional income other than retirement benefits. At the time of "ageing" cities, it is necessary to prepare well in advance existing production facilities to employ a number of retired people by adapting machinery and technological processes and observing working terms and conditions in accordance with age peculiarities.

2. Education and the opportunity to receive it after retirement is an important factor of aged people's social activity. At the municipal level, it is necessary to provide aged people with the opportunity for vocational training and retraining and develop educational training programs. It is also important to carry out among the aged population awarenessraising campaigns on the availability of educational opportunities.

3. The provision of high-quality and affordable social services for aged people is the next important area in addressing population ageing. Nowadays, such services are provided mainly by government organisations. The private sector does not play a big role in this industry. However, given the scale of needs in social services and the forecast increase in the number of aged people, it is necessary to stimulate the expansion of the private social services sector through the development of various forms of municipal and private partnership in the city's economy as well as involve volunteers, develop mobile forms of social services and increase the social responsibility for the support and care of aged relatives through the expansion of legal and economic instruments (allowances, tax deductions, reduced payment for housing services etc.).

4. Maintaining social activity of aged people, giving them the opportunity to participate in the social and cultural life of the city may be another area of activity for municipal authorities.

5. The fight against cruelty towards aged people is also an objective of local authorities. Unfortunately, this phenomenon occurs in our country and manifests itself not only in hospitals and nursing homes but also in families. One of the solutions to this challenge may be a prompt response to all cases of illtreatment or lack of care and access to sources of information and mechanisms which could make it possible to report such cases.

6. The development of co-working and co-living for aged people which could enable them to express their creativity, meet the needs for communication and social interaction or gather in small "communities" to have a life while receiving care and support.

Given the costly nature of all of the aforementioned measures to address the challenge of "ageing" cities, it is necessary to develop a mechanism for their funding within the framework of existing and planned regional and municipal targeted programs.

\section{References}

[1] The city in the context of global processes // Under red. I. Abylgaziev, I. V., Lin, N.. See. - M., 2011. [Gorod v kontekste global'nykh protsessov // Pod red. I.I. Abalgazieva, I.V. Il'ina, N.A. Sluki. - M., 2011.]

[2] Vasin S. Russia is aging worse than other countries // Demoscope Weekly. 2008. - 15-31 December. No. 357-358. [Vasin S. Rossiya stareet khuzhe drugikh stran // Demoskop Weekly. 2008. - 15-31 dek. № 357-358.]

[3] Novoselova E. N. The aging of the population of global cities (on example of Moscow) // Vestnik of Moscow University. Ser. 18. Sociology and political science. - 2015. - No. 4.[Novoselova E.N., Starenie naseleniya global'nykh gorodov (na primere Moskvy) // Vestnik moskovskogo un-ta. Ser. 18. Sotsiologiya i politologiya. - 2015. - № 4.]

[4] Sajt Istorichekie materialy. - http://istmat.info

[5] Oficial'nyj sajt Federal'noj sluzhby gosudarstvennoj statistik. http://www.gks.ru/wps/wcm/connect/rosstat main/rosstat/ru/statistics/po pulation/demography/

[6] Ageing in Cities (OECD Publishing, Paris). The full publication is available on the OECD iLibrary at http://dx.doi.org/10.1787/9789264231160-en.oecd 2015

[7] Buffel, T. et al. (2012): Ageing in urban environments: Developing 'agefriendly' cities // Critical Social Policy, Vol. 32, No. 4, pp. 597-617, http://dx.doi.org/10.1177/0261018311430457.

[8] Feldstein, Martin S. (2006): The effects of the ageing European population on economic growth andbudgets: implications for immigration and other policies. // NBER Working Paper Series Working Paper 12736,http://www.nber.org/papers/w12736

[9] Oliveira Martins, J. et al. (2005): The impact of ageing on demand, factor markets and growth // OECD Economics Department Working Papers, No. 420, OECD Publishing, Paris, http://dx.doi.org/10.1787/545827207132.

[10] OECD (2013b), Pensions at a Glance: OECD and G20 Indicators, OECD Publishing, Paris, http://dx.doi.org/10.1787/pension_glance2013-en.

[11] OECD (2015), The Metropolitan Century: Understanding Urbanisation and its Consequences, OECD Publishing, Paris, http://dx.doi.org/10.1787/9789264228733-en.

[12] Gostishchev V. K., Glagolev N. With. Health and social aspects and trends of population aging of Russia and European countries // Bulletin of Belgorodsk. state University. Ser. Medicine. Pharmacy. - 2014.- T/26. - No. 11 (182). [Gostishchev V.K., Glagolev N.S. Mediko-sotsial'nye aspekty i tendentsii stareniya naseleniya Rossii i otdel'nykh evropeiskikh stran // Nauchnye vedomosti Belogorodsk. gos. un-ta. Ser. Meditsina. Farmatsiya. - 2014.- T/26. -№ 11 (182).]

[13] Rejting tsran mira po urovnyu prodolzhitel'nosti zhizni. http://gtmarket.ru/ratings/life-expectancy-index/life-expectancy-indexinfo.

[14] Antonov, A. I., Dynamics of population of Russia in the XXI century and the priorities of the demographic policy [Text] / A. I. Antonov, V. A. Borisov. - Moscow: Klyuch-C, 2006. - 192 p.[Antonov, A.I. Dinamika naseleniya Rossii v XXI veke i prioritety demograficheskoi politiki [Tekst] / A.I. Antonov, V.A. Borisov. - M.: Klyuch-S, 2006. 192 s.]

[15] Antonov A. I., Sorokin S. A. the fate of the family in Russia of XXI century. - M.: "Grail", 2000. [Antonov A.I., Sorokin S.A. Sud'ba sem'i v Rossii KhKhI veka. - M.: «Graal'», 2000.]

[16] Medkov V. M. the depopulation Bomb: the experience of Russia results and lessons / Medkov V. M. // Bulletin of Moscow University. Series 18. Sociology and political science. 2000. - No. 4. - P. 45-49.[Medkov V.M. Bomba depopulyatsii: opyt Rossii itogi i uroki / V.M. Medkov // Vestnik Moskovskogo universiteta. Seriya 18. Sotsiologiya i politologiya. 2000. - № 4. - S. 45-49.] 